\title{
Fabrication and Performance Evaluation of a Thevetia Nut Cracking Machine
}

\author{
M. M. Odewole*, R. O. Ajibade \\ Department of Agricultural and Biosystems Engineering, University of Ilorin. P.M.B. 1515, Ilorin, Nigeria.
}

\begin{abstract}
Thevetia seed contains about 64 percent of non-edible oil in its oily kernel and this oil can be used for various purposes such as biofuel and bio-oil; making of paints, insecticides, cosmetics, lubricants and cooling oil in electrical transformers. The cakes obtained after oil extraction are incorporated on the field as manure. In order to get quality oil kernels from the hard nuts, there is need to properly crack them; this process of cracking is still a great challenge. As result of the aforementioned problem, this work focused on the design, fabrication and performance evaluation of a thevetia nut cracking machine. The machine works based on the principle of attrition force. Some of the parts designed for were diameter of shaft ( 13 $\mathrm{mm}$ solid shaft) and length of belt (A55), power required to operate the machine $(2.5 \mathrm{hp})$, speed of operation $(9.14 \mathrm{~m} / \mathrm{s})$ and the appropriate dimension of angle iron bar of $45 \mathrm{~mm} \times 45 \mathrm{~mm} \times 3 \mathrm{~mm}$ was used for the structural support. The fabrication was done systematically followed by the performance evaluation of the machine. The result of the overall cracking efficiency and throughput capacity of the machine were evaluated to be $96.65 \%$ and $510 \mathrm{~g}$ /min respectively.
\end{abstract}

KEYWORDS: thevetia nut, thevetia kernel, design, attrition, overall cracking efficiency

[Received August 28 2014; Revised March 92015 \& May 14 2015; Accepted June 6 2015]

\section{INTRODUCTION}

Thevetia plant (Thevetia peruviana) shown in Figure 1 is a dicotyledoneous flowering plant which belongs to the order of Apocynales and family of Apocynaceae (Usman et al, 2009 and Odiko, 1988). The plant is an erect $(3-4.3 \mathrm{~m})$ perennial shrub that originated from Central America and it is mostly found in the tropics and sub-tropics region of the world. The plant has the following common names physic plant, milk bush, allamanda plant, yellow oleander and "olomi ojo" in Yoruba (Ibiyemi et al, 2002). One plant tree produces 400 800 fruits/year, depending on rainfall and plant age (Ibiyemi et al, 2002). The seed contains about 60-64 percent oil which can be used for making biofuel, paints, insecticides, cosmetics, animal feeds-if detoxified (Atteh et al, 1990), lubricants and coolant. It also contains 30-35 percent protein and the kernel fraction in fruit of thevetia nut is only $16.14 \%$ (Ibiyemi et al, 2002). The cake derived after oil extraction can be added to the soil as manure and the hard seed coat (endocarp) derived after nut cracking can be processed to particle board for making furniture or turned to briquette and used as heat source.

George (1992) and Obadofin (1991) reported the following engineering properties of thevetia seed: surface area $\left(10.54 \mathrm{~cm}^{2}-23.76 \mathrm{~cm}^{2}\right)$; angle of repose $(0.36 \mathrm{rad})$;

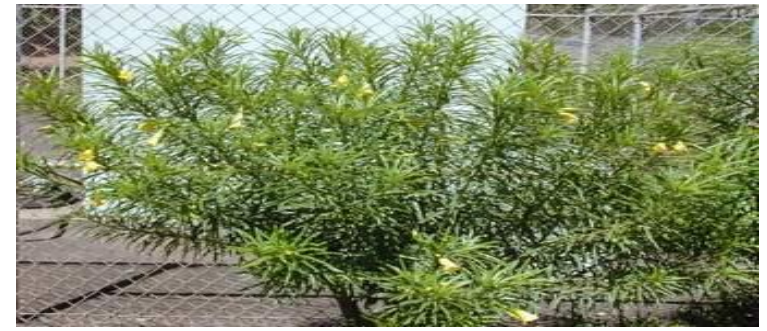

Figure 1: Thevetia plant.

*Corresponding author's e-mail address: odewole2005@yahoo.com

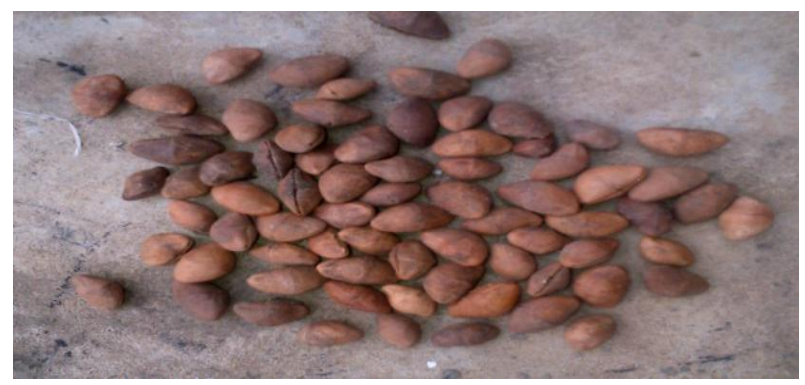

Figure 2: Thevetia nuts.

volume $\left(1.80 \mathrm{~cm}^{3}-6.10 \mathrm{~cm}^{3}\right)$; and terminal velocity of $11.43 \mathrm{~m} / \mathrm{s}$.

Cracking is one of the unit operations of agricultural processing. It is the formation of fracture on the outer surface of material which will aid the recovery of kernels. Cracking can be achieved through the application of forces on materials in various forms: impact, compression or attrition. Some of the important theories governing cracking operations are stated and explained by the following authors: Freund (1990); Gol'dstein and Salganik (1974); Leblond (1989); Adda-Bedia et al. (1999); Ravichandar and Knauss (1984); Fineberg et al. (1992); and Boudet et al. (1996).

Methods of cracking can be broadly classified into two; these are traditional method and modern method. The traditional method can take place in the following forms: stones arrangements, and mortar and pestle. This method is full of drudgery; the output is low and can cause serious injuries to human being. The modern method involved the use of specialized machines/equipment like hammer mill, roller mill, centrifugal cracker, laser beam cracker, attrition mill and others to offset the demerits of traditional methods. 
Patel (1980) invented a method for cutting macadamia nut shell into two half spheres by using a carbon dioxide laser beam. The high power cutting beam laboratory experiments on cutting single nut indicated nearly $100 \%$ recovery of whole kernels. Olaniyi (2002) constructed and tested Palm nut cracker. The machine was tested for efficiency, mechanical damage and cracking efficiency to be $73 \%, 12 \%$ and $74 \%$ respectively. Adebayo (2004) developed and carried out the performance evaluation of a motorized hammer mill palm- nut cracking machine. The result of various tests gave 90\% performance efficiency, $85 \%$ cracking efficiency and $14 \%$ percentage broken at a cracking speed of $1440 \mathrm{rpm}$. Sodiq (1991) designed and constructed a thevetia nut cracker using centrifugal force to achieve the cracking, the machine could not be tested due to some constraints, however, the power required to drive the machine and speed were designed to be $15 \mathrm{hp}$ and $2702 \mathrm{rpm}$ respectively.

In order to get a high quantity of oil from the kernel and harness other benefits of the seed, there is need to properly remove the kernels from the hard nut in which it is enclosed. This is still a serious challenge as many available methods have not been able to do this without causing serious unbearable damage to the useful kernel that contains the oil, which in turns lowers the quantity of oil that can be obtained. Therefore, the main objective of this work was to design, fabricate and evaluate the performance of a motorized thevetia nut cracking machine. The work created a better means of reducing drudgery and time loss in thevetia nut processing; increased the availability of good quantity of quality kernels for oil extraction, and increased the quantity of other by-products from the nut for both industrial and domestic uses.

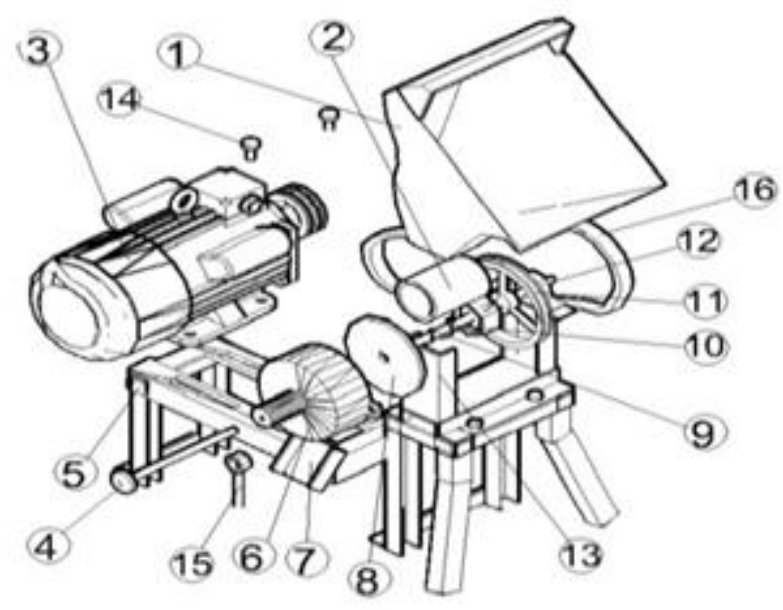

Legend: 1- Hopper, 2 - Conveyor, 3 - Electric Motor, 4 -Regulating Wheel, 5-Frame, 6 - Cracking Drum, 7 - Nut Outlet Guide, 8 - Disc Blade, 9 - Shaft, 10 - Disc Blade, 11- Pulley, 12 - Bearing, 13 - Casing, 14 - Bolt, 15 - Regulating Wheel Handle, 16 - Belt

Figure 3: Isometric view of the machine in the making.

\section{MACHINE DESCRIPTION AND WORKING PRINCIPLE}

The machine, shown in Figure 3, is made up of a hopper that took the form of a truncated inverted pyramid; the hopper is slightly bent to one side in order to prevent the escape of seeds during operation. A short cylindrical barrel is directly welded to the lower part of the hopper. The machine also consists of a worm screw which passed across the barrel internally and extends to the cracking drum of the machine and the pillow bearing that opposes the upward reaction of the worm screw in operation. The internal parts of the cracking drum of the machine is made up of two disc plates with abrasive surfaces, one of the plates is stationary and the other rotates in the direction of the worm screw. The external parts of the cracking drum is also made of up a discharge chute, and protruding internal hollow screw with a cylindrical cross section which houses another external screw that holds a lock nut with a short handle and a friction ball. The machine is powered by $2.5 \mathrm{hp}$ electric motor which transmits motion from its driving (small) pulley to the big (driven) pulley on the worm screw. All the components of the machine are rigidly attached to the structural frame of the machine made of mild steel.

To operate the machine, it is first allowed to run empty for about 30 seconds before it is loaded with seeds to be cracked. The seeds fed into the hopper fall on the rotating worm screw which conveys them to the cracking drum. Before commencing the major cracking operation, it is necessary to carry out the setting of the space between the two abrasive cracking plates with some seeds so as to achieve a better cracking and to prevent unusual escape of whole seeds. The space between the two abrasive disc plates is adjusted with the external screw placed inside the protruding internal hollow screw. When a suitable space for better cracking is achieved, the lock nut on the external screw is tightened in order to keep the space constant throughout the operation. The cracking of seeds to bring out the needed oily kernels is achieved through the compressive and shearing actions between the two abrasive disc plates when the seeds fell in between them. After cracking, the oily kernels, escaped whole nuts, hard nuts without kernels and other by-products of the cracking operation would pass through the discharge chute into a container, after that, separation of end products of cracking into various components would be done.

\section{MACHINE ELEMENTS DESIGN}

\section{A. Design Considerations}

In designing the thevetia cracking machine, the following factors were considered: seed orientation that would give a minimal or no damage to the kernel, minimum escape of whole seeds, low power requirement, fair construction cost, structural stability and good finishing. Equations (1-18) for design of components were as obtained from (Khurmi and Gupta, 2005), and (Robert, 1985). 


\section{B. Determination of Force Required to Crack the Nut with Minimum Damage to the Kernel}

The experiment to determine the force required to break the thevetia nut with respect to different seed orientations was carried out at the National Centre for Agricultural Mechanization laboratory, Ilorin-Lokoja Express way, Idofian, Kwara State, Nigeria; using the Universal Testing Machine (M500-100AT Testometric). Fifteen (15) samples of thevetia nuts were used. Five (5) samples for longitudinal, five (5) samples for lateral and five (5) samples for axial. The lateral orientation of the seed gave the best crack with minimum damage to the kernel and the average value of force required to cause the crack was $1000 \mathrm{~N}$. This value of force was used for further design.

\section{Shaft Design}

To determine the shaft diameter, Figure 4 is used.

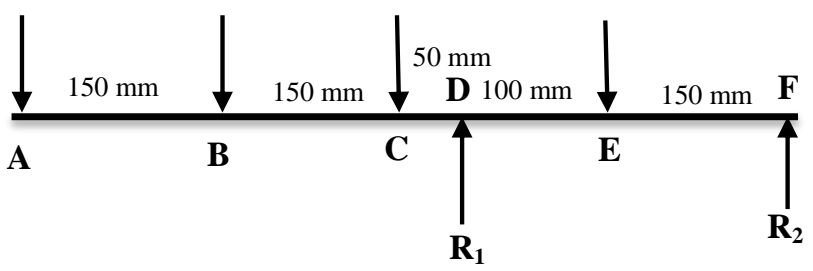

Figure 4: The free body diagram to determine the shaft diameter.

$\sum F_{y}=0 ; \quad \sum M R_{2}=0 ; R_{1}=414 N ; R_{2}=-104 N$

Bending moment at $A=0$

Bending moment at $B=-1500 \mathrm{Nmm}$

Bending moment at $D=-3100 \mathrm{Nmm}$

Bending moment at $F=0$

Therefore, maximum bending moment is at

Twisting moment:

$$
D \text { is }-3100 \mathrm{Nmm}
$$

$$
T_{e}=\sqrt{(K m \times M)^{2}+\left(K_{t} \times T\right)^{2}}
$$

Where, $K_{m}=2$ (Assumed combined shock and fatigue factor for bending).

$K_{t}=2$ (Combined shock and fatigue factor for torsion)

$K_{m}$ and $K_{t}$ based on the nature of the load (suddenly applied load with minor shocks)

$$
\begin{aligned}
& T_{e}=\sqrt{(2 \times 3100)^{2}+(2 \times 16870)^{2}}=70586 \\
& T_{e}=\frac{\pi}{16} \times \tau \times d^{3}
\end{aligned}
$$

Where, $\tau=650 \mathrm{MPa}$ (Assumed Ultimate tensile strength); $\mathrm{d}=$ diameter of the shaft (in $\mathrm{mm}$ )

$$
d^{3}=553 \quad \text { Therefore, } d=8.21 \mathrm{~mm}
$$

Equivalent bending moment,

$$
\begin{gathered}
M_{e}=1 / 2\left[K m \times M+\sqrt{(K m \times M)^{2}+(K t \times T)^{2}}\right] \\
M_{e}=1 / 2[K m \times M+T e] \\
M_{e}=\frac{\pi}{32} \times \sigma \times d^{3}
\end{gathered}
$$

Where, $\sigma=$ Assumed Yield strength, MPa

$d=$ diameter of the shaft

$66293=\frac{\pi}{32} \times 350 \times d^{3}$

Therefore, $\quad d=12.45 \mathrm{~mm}$
Taking the larger of the two values, a shaft with $13 \mathrm{~mm}$ diameter was used in the study.

\section{Pull Design}

Assuming the diameter of the motor pulley, $D 1=125 \mathrm{~mm}$, speed of motor pulley, $N 2=1400 \mathrm{rpm}$, and speed of shaft pulley, $N 1=900 \mathrm{rpm}$, using eqn (5), the diameter of the shaft pulley, D2 $=194.4 \mathrm{~mm}$.

$$
\frac{\mathrm{N} 2}{\mathrm{~N} 1}=\frac{\mathrm{D} 1}{\mathrm{D} 2}
$$

\section{E. Belt and Angle of Wrap Design}

Belt speed, $\mathrm{V}=\frac{\pi \mathrm{DN}}{60}=9.14 \mathrm{~m} / \mathrm{s}$

Length of belt $(L)$

$$
L=\frac{\pi}{2}(\mathrm{D} 1+\mathrm{D} 2)+2 \mathrm{C}+\frac{(\mathrm{D} 1-\mathrm{D} 2)^{2}}{4 \mathrm{x}}=1230.1 \mathrm{~mm}
$$

Subtracting $36 \mathrm{~mm}$ for type A belt. The standard inside length $=1230-36=1194 \mathrm{~mm}$. The pitch length is obtained by adding $36 \mathrm{~mm}$ to inside length. This is close to $1219 \mathrm{~mm}$ in the list of standard tables for selection of pitch length. Adding $36 \mathrm{~mm}$ to this gives; Standard pitch length $\left(L_{1}\right)=$ $1219 \mathrm{~mm}+36 \mathrm{~mm}=1255 \mathrm{~mm}$.

Calculating new the center distance, $x^{1}$ using eqn (7),

$$
L_{1}=\pi\left(r_{1}+r_{2}\right)+2 C^{1}+\left(r_{1}-r_{2}\right) / C^{1} \cdot
$$

$C^{1}=637 \mathrm{~mm}$. Hence new center distance is $637 \mathrm{~mm}$

For the angle of wrap $(\theta)$ for the pulley

$$
\theta=180-2 \operatorname{Sin}^{-1}\left[\frac{D 1-D 2}{2 C}\right]
$$

Center distance, $C=637 \mathrm{~mm}$, therefore $\theta \approx 175^{\circ}$.

\section{F. Power Required to Operate the Machine Power $=P_{f}+P_{m}+P_{p}+P_{c}$}

where, $P_{f}=$ power to overcome inertia of the part.

$P_{m}=$ power to move the moving parts.

$P_{p}=$ power to convey the product.

$P_{c}=$ Power to crack the nut

$$
\begin{aligned}
& P_{f}=W \times V \\
& W=W_{D}+W_{T}+W_{S}+W_{P}
\end{aligned}
$$

where, $W=$ total weight, $W_{D}=$ weight of disk, $W_{T}=$ weight of thread.

$W_{S}=$ weight of shaft, $W_{P}=$ weight of pulley

$W=2+50+50+50=152 N$

$V=$ velocity

$$
V=\frac{\pi D N}{60}=\frac{3.142 \times 0.02 \times 900}{60}=0.94 \mathrm{~m} / \mathrm{s}
$$

where, $D=$ assume average diameter $(\mathrm{m})$

$$
V=900 \mathrm{rpm}=0.94 \mathrm{~m} / \mathrm{s}
$$

Substituting eqns (3) and (4) into eqn (2)

$P_{f}=152 \times 0.94=143.26 \mathrm{~W}$

$P_{m}=P_{f}=143.26 \mathrm{~W}$

Since the power to overcome the inertia will move the moving part, eqn (13) could be used.

$$
P_{p}=W S O T \times V
$$

where, $W S O T=$ Weight of seed on the thread,

Therefore, $\quad P_{p}=50 \times 0.94=47 \mathrm{~W}$

$P_{c}=T F C \times V$

where, $T F C=1000 \mathrm{~N}(T F C=$ Cracking force from UTM $)$ Therefore, $P_{c}=1000 \times 0.94=940 \mathrm{~W}$ Total Power $=143.26+143.26+47+940=1273.52 \mathrm{~W}$ 
Power to operate the machine $=$

Total power/assumed efficiency

$\frac{1274}{0.8}=1592 \mathrm{~W}=1.59 \mathrm{~kW}=2.12 \mathrm{hp}$

A $2.5 \mathrm{hp}$ electric motor will be safe for the machine.

\section{G. Design of Structural Support}

The structural support is made of mild steel angle iron of $3 \mathrm{~mm}$ thickness; and consists of both vertical and horizontal members. Its function is to safely carry all the loads of the machine. In order to design for the support, two possible failures that could occur were considered; these are buckling (for vertical members) and bending (for horizontal members). The design should ensure the non-failure of the vertical and horizontal members via buckling and bending respectively.

(i) Design of vertical members: The design of vertical members was done by determining the buckling load of the vertical members of the support due to the critical weight of the machine using Euler's equation in (16):

$$
W_{c r}=\frac{C_{f E A \pi^{2}}}{\left(\frac{l_{c}}{k}\right)^{2}}
$$

where, $W_{c r}$ is the buckling load, $\mathrm{E}$ is the modulus of elasticity (Young's modulus) for the material of the vertical member (i.e. mild steel), $\mathrm{A}$ is the cross sectional area of the vertical member (column), $\mathrm{k}$ is the radius of gyration of the column's cross section, $l_{c}$ is the length of the column and $c_{f}$ is a constant known as fixity coefficient. The vertical member has a rectangular cross-section; for a rectangular cross-section, $\mathrm{k}$ is determined using expression;

$k=\frac{h \sqrt{3}}{6}$; where $\mathrm{h}$ is the smaller dimension of the rectangular cross-section. $c_{f}$ is 0.25 because one end is fixed and the other free $\mathrm{E}=200 \mathrm{GN} / \mathrm{m}^{2}, \mathrm{~A}=105 \mathrm{~mm}^{2}, l_{c}=440 \mathrm{~mm}, \mathrm{~h}=$ $3 \mathrm{~mm}$; hence $k=0.8660$ And $W_{c r}=0.2007 M N \approx$ $200.7 k N$ (Khurmi and Gupta 2005)

It was also important to determine the safe load, and it was determined using equation 17

$$
W_{s a}=\frac{W_{c r}}{F_{s a}}
$$

where $W_{s a}$ is the safe load and $F_{s a}$ is the factor of safety. $W_{c r}$ is $200.7 \mathrm{kN}$ and $F_{s a}=1.2$. Hence, $W_{s a}=167.25 \mathrm{kN}$ since the safe load is significantly greater than actual load i.e $W=$ the total load to be carried by the structural support which is $1.22 \mathrm{kN}$. From steel table, the mild steel angle bar suitable for this design is $45 \mathrm{~mm} \times 45 \mathrm{~mm} \times 3 \mathrm{~mm}$.

(ii) Design of Horizontal Members: In the design of the horizontal members (beams) of the support, the sectional of modulus $(\mathrm{Z})$ of the horizontal members was determined using Equation 18.

$$
Z=\frac{W l_{b}}{4 \delta_{0}}
$$

Where $l_{b}$ is the length of the beam $(840 \mathrm{~mm})$ and $\delta_{0}$ is the yield stress $\left(200 \mathrm{~N} / \mathrm{mm}^{2}\right)$, therefore, $Z=0.1596 \mathrm{~cm}^{3}$ From the table of equal angles, the dimension of mild steel angle bar suitable for the design is $45 \mathrm{~mm} \times 45 \mathrm{~mm} \times 3 \mathrm{~mm}$; this dimension will carry the machine without failure.

\section{FABRICATION PROCESS}

Figure 5 shows the orthographic projection of the machine. Mild steel was used to fabricate all the parts of the machine. For the structural support, mild steel angle iron with dimension $45 \mathrm{~mm} \times 45 \mathrm{~mm} \times 3 \mathrm{~mm}$ was used all through based on the design; and mild steel sheet of thickness $2 \mathrm{~mm}$ was used for other major parts of the machine. All the dimensions were marked out, cut, turned, welded and assembled based on the specifications earlier determined in the design process.
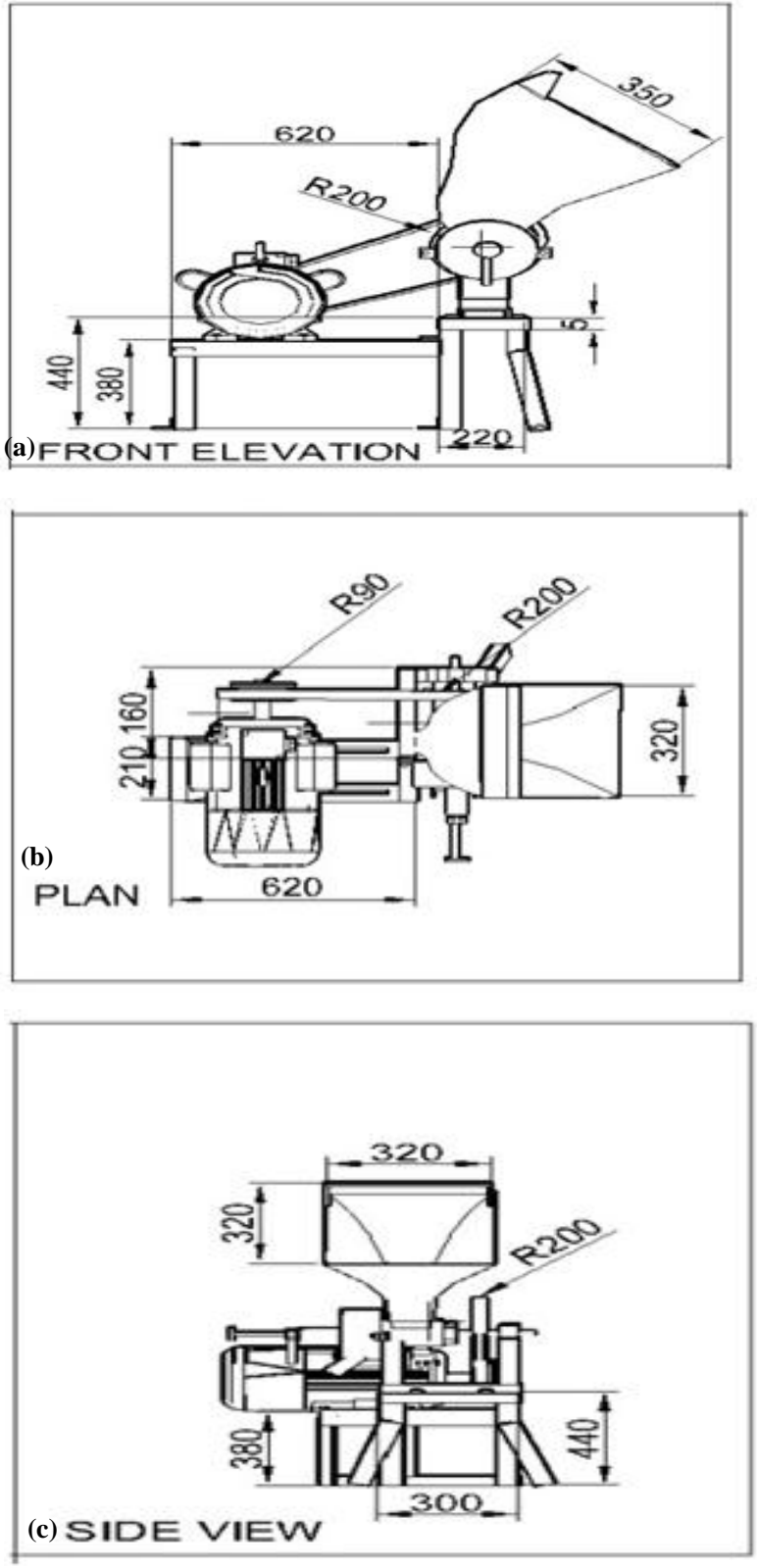

Figure 5: Orthographic projection of the machine.

Figure 6 shows the photograph of the fabricated machine. 


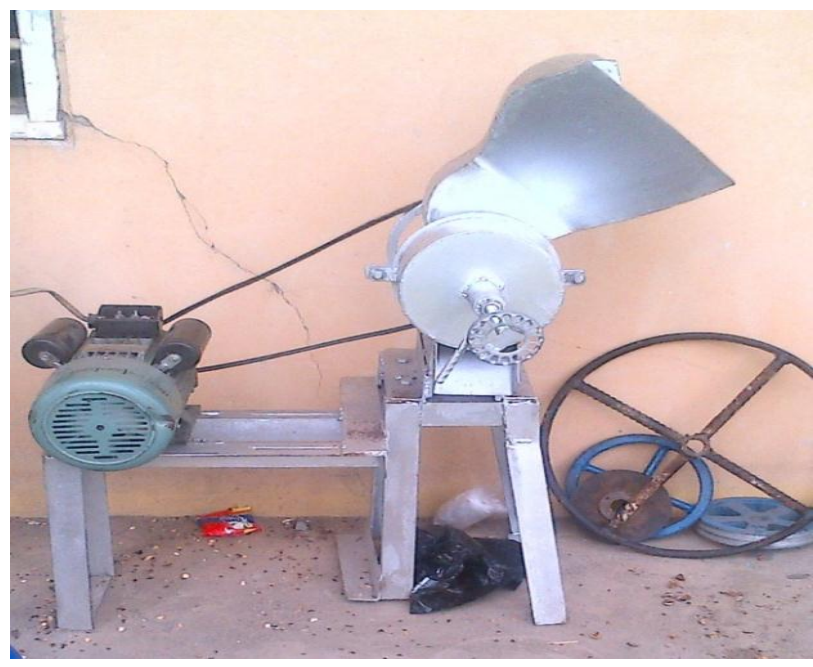

Figure 6: The fabricated cracking machine.

\section{PERFORMANCE EVALUATION OF THE MACHINE}

After fabrication, the machine was subjected to a preliminary test in order to determine its cracking efficiency and the throughput capacity. Thevetia seeds were procured and sorted in order to get better material for the test. The machine was actuated and allowed to run empty for about 30 seconds before loading with seeds. Before the main test, few seeds were fed into the machine in order to set the appropriate gap between the two cracking discs plates in the cracking drum which would prevent much escape of whole nuts. The total mass of thevetia nuts fed into the machine was $7500 \mathrm{~g}$. Fifteen (15) runs were carried out on the machine; for each run, $500 \mathrm{~g}$ of thevetia were fed into the machine during which the time to complete the cracking was taken with a stop watch (NOKIA X2-01).

All the cracked samples were carefully collected, and were manually separated into various components (kernel, partially cracked, shells and escaped whole seed). The performance indices used are as stated and evaluated below:

Overall Cracking Efficiency $(\%)=\frac{M I-M P+M E}{M I} \times 100$

$$
=\frac{7500-(311+15.4)}{7500} \times 100=95.65 \%
$$

The throughput capacity of the machine $=\frac{M I(g)}{T(\min )}=$

$$
\frac{7500 \mathrm{~g}}{14.7}=510 \mathrm{~g} / \mathrm{min}
$$

where $M I$ is mass introduced, $M P$ is mass of partially cracked, $M E$ is total number mass of escaped whole nuts, and $T$ is time.

The cracking efficiency was evaluated to be $95.65 \%$ and the capacity of the machine was evaluated to be $510 \mathrm{~g} / \mathrm{min}$. Figures $10-13$ show the pictorial views some of the results of the performance evaluation.

\section{RESULTS AND DISCUSSION}

The result of the performance evaluation is presented in Table 1. The table shows that out of the total mass of $7500 \mathrm{~g}$ of thevetia nuts introduced into the machine for performance evaluation, $965.8 \mathrm{~g}$ of kernels, $311 \mathrm{~g}$ of partially cracked nuts,
$5946 \mathrm{~g}$ of shells, $15.4 \mathrm{~g}$ of escaped whole seeds and $261.8 \mathrm{~g}$ of waste were obtained.

The total time of operation was 884 seconds (14.7 min.). The highest and lowest times of operations were 64 seconds and 54 seconds respectively. The highest waste of $58 \mathrm{~g}$ was recorded at the early stage of the performance evaluation experiment; this was the time at which the machine was being set for effective cracking operation. Shown in Figures 7 and 8 are partially cracked seeds and post crack kernels respectively.

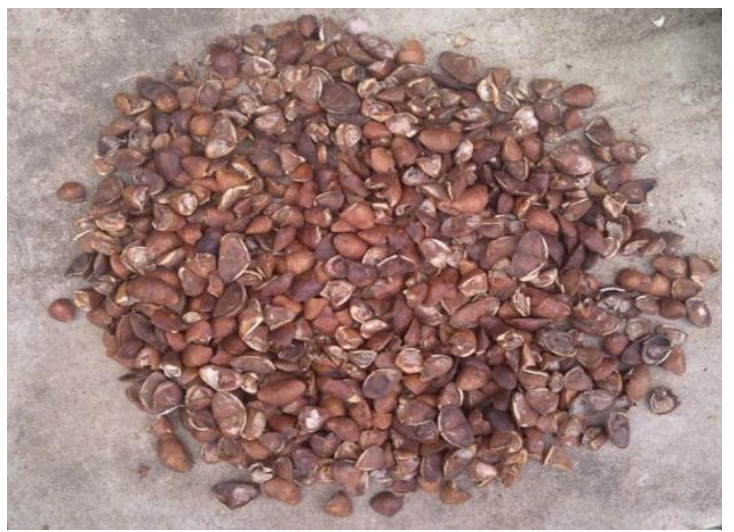

Figure 7: Partially cracked seeds.

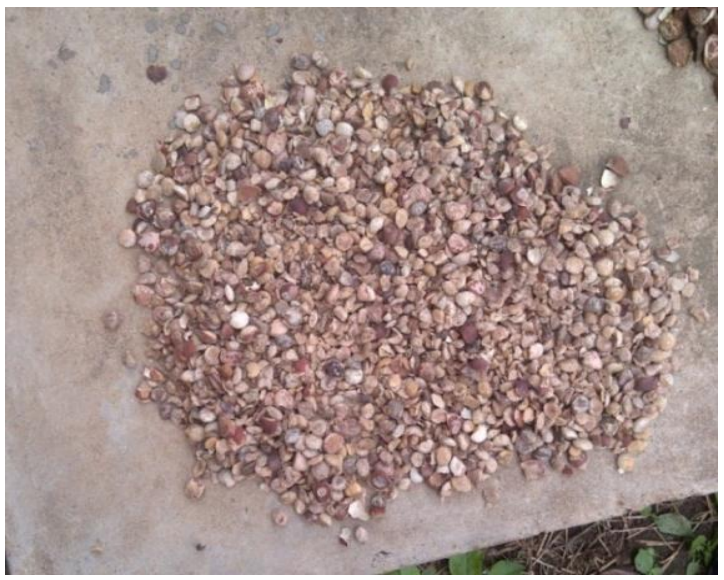

Figure 8: Kernels (after cracking).

Table 1: Data obtained from Performance Evaluation of the Machine.

\begin{tabular}{lcccccc}
\hline S/N & $\begin{array}{c}\text { Kernel } \\
(\mathbf{g})\end{array}$ & $\begin{array}{c}\text { Partially } \\
\text { cracked } \\
\text { seeds }(\mathbf{g})\end{array}$ & $\begin{array}{c}\text { Shell } \\
(\mathbf{g})\end{array}$ & $\begin{array}{c}\text { Escaped } \\
\text { whole } \\
\text { seeds } \mathbf{( g )}\end{array}$ & $\begin{array}{c}\text { Wastes } \\
(\mathbf{g})\end{array}$ & $\begin{array}{c}\text { Time } \\
(\mathbf{s e c s})\end{array}$ \\
\hline 1 & 68.9 & 17.3 & 409 & - & 4.8 & 58 \\
2 & 57.2 & 32.5 & 379 & 2.30 & 19.0 & 61 \\
3 & 55.0 & 14.2 & 371 & 1.80 & 58.0 & 62 \\
4 & 56.5 & 20.2 & 366 & - & 57.3 & 56 \\
5 & 71.7 & 15.3 & 413 & - & 0.0 & 57 \\
6 & 60.0 & 34.5 & 405 & 1.70 & 0.80 & 59 \\
7 & 68.9 & 21.0 & 395 & 2.3 & 12.8 & 60 \\
8 & 72.0 & 13.2 & 414 & - & 0.80 & 63 \\
9 & 60.2 & 24.2 & 381 & - & 14.6 & 61 \\
10 & 68.3 & 10.4 & 400 & - & 18.3 & 57 \\
11 & 63.0 & 15.1 & 385 & - & 22.8 & 64 \\
12 & 72.1 & 22.3 & 418 & - & 11.5 & 54 \\
13 & 69.8 & 29.2 & 409 & 4.30 & 1.80 & 57 \\
14 & 60.5 & 24.2 & 401 & - & 16.2 & 58 \\
15 & 59.7 & 13.4 & 398 & - & 13.1 & 56 \\
Total & $\mathbf{9 6 5 . 8}$ & $\mathbf{3 1 1 . 0}$ & $\mathbf{5 , 9 4 6}$ & $\mathbf{1 5 . 4}$ & $\mathbf{2 6 1 . 8}$ & $\mathbf{8 8 4}$ \\
\hline
\end{tabular}


The highest waste of $58 \mathrm{~g}$ was recorded at the early stage of the performance evaluation experiment; this was the time at which the machine was being set for effective cracking operation. The cracking efficiency was evaluated to be 95.65 $\%$ and the capacity of the machine was evaluated to be 510 $\mathrm{g} / \mathrm{min}$. Figures 10 - 13 show the pictorial views some of the results of the performance evaluation.

\section{CONCLUSION}

A Thevetia nut cracking machine was designed, fabricated and tested. The performance of the machine in terms of overall cracking efficiency was estimated at $96.65 \%$ while the throughput capacity of $510 \mathrm{~g} / \mathrm{min}$ was obtained. These values are considered appreciable enough. Thus, the machine is suitable for cracking thevetia nuts. The use of the machine will reduce the drudgery encountered in cracking of thevetia nuts as well as increase the quantity of quality kernels needed for subsequent oil extraction process.

\section{REFERENCES}

Adda-Bedia, M.; Arias R.; Ben-Amar, M.; and Lund, M. (1999). Generalized Griffith criterion for dynamic fracture and the stability of crack motion at high velocities. Phys Rev E, 60:2366-2376.

Adebayo, A. A. (2004). Design and Fabrication of a Palm- Nut Cracking Machine. The Nigeria Institute of Agricultural Engineering Proceeding, 26: 326- 330.

Atteh, J. O.; Ibiyemi, S. A.; Onadepo, F. A. and Ugboma, O.O. (1990). Replacement of Palm Oil by Thevetia Oil in Broiler Chicks. Journal of Agricultural Science. Cambridge, 115: 141-143.

Boudet J. F., Ciliberto S. and Steinberg V. (1996). Dynamics of crack propagation in brittle materials. $\mathrm{J}$ de Physique II, 6:1493-1516.

Fineberg J., Gross S.P., Marder M., and Swinney H.L. (1992). Instability in the propagation of fast cracks. Phys Rev B, 45:5146-5154.

Freund L.B. (1990). Dynamic fracture mechanics. Cambridge University Press, Cambridge.
George, E. (1992). Aerodynamic Properties of Allamanda (Thevetia Peruviana) and Preliminary Design of A Separator. Unpublished B.Eng Thesis. Department of Agricultural Engineering, University of Ilorin, Ilorin, Nigeria.

Gol'dstein R. V. and Salganik R. L. (1974). Brittle fracture of solids with arbitrary cracks. Int $\mathbf{J}$ Fracture, 10:507-523.

Ibiyemi S. A.; Fadipe V. O.; Akinremi O. O and Bako S. S. (2002). Variation in Oil Composition of Thevetia Peruviana Jyss (Yellow Oleander) Fruits Seeds, J. Appl. Sci Environ. Mgt. (JASEM), 6(2): 61 - 65.

Khurmi R. S. and Gupta J. K. (2005). Textbook of Machine Design, S. Chand Eurasia publishing house (pvt.) Ltd, Ram Nagar, New Delhi.

Leblond J. B. (1989). Crack paths in plane situations-I. General form of the expansion of the stress intensity factors. Int J Solids Structures, 25: 1311-1325.

Obadofin, J. M. (1991). The Physical Properties of Thevetia Seeds. Unpublished B.Eng Project Report. Department of Agricultural Engineering, University of Ilorin, Ilorin.

Odiko, A. I. (1988). Effect of Heat Treatment of Dietary Thevetia Cake on Growth Performance and Nutrient Retention in Broiler Chickens. Unpublished B.Agric Project Report. Department of Animal Production, University of Ilorin, Ilorin, Nigeria.

Olaniyi, M. O., (2002). Design, Fabrication and Performance Evaluation of a Palm- Nut Cracking Machine. Unpublished HND Thesis. Agricultural Engineering Department, Kwara State Polytechnic, Ilorin.

Patel, C. K. (1980). Method for shelling of nuts with laser beam, us Patent 4358467. Practice, University of Guelph, Ontario.

Ravi-Chandar K. and Knauss, W. G. (1984). An experimental investigation into dynamic fracture on steady state crack propagation and crack branching. Int J Fracture, 26:141-154.

Usman, L. A., Oluwaniyi, O. O., Ibiyemi, S. A., Muhammad, N. O. and Ameen, M. O. (2009): The Potential of Oleander (Thevetia peruviana) in Africa Industrial Industry Development: A Case Study of Nigeria. Journal of Applied Biosciences, 24: 1477-1487. 